\title{
Actualidades en la inmunopatología de la esclerosis múltiple
}

\author{
Carlos Fredy Cuevas-García, Nora Hilda Segura-Méndez y Diana Andrea Herrera-Sánchez
}

Instituto Mexicano del Seguro Social, Centro Médico Nacional Siglo XXI, Hospital de Especialidades "Dr. Bernardo Sepúlveda Gutiérrez", Ciudad de México, México

\begin{abstract}
Resumen
La esclerosis múltiple es una enfermedad inflamatoria desmielinizante que afecta el sistema nervioso central. Su etiología es el resultado de una compleja interacción entre factores genéticos y ambientales que desencadenan una respuesta inmune desregulada, con la consiguiente inflamación y degeneración neuronal/axonal. La neuroinflamación se desencadena cuando los leucocitos periféricos migran al sistema nervioso central y liberan citocinas como interleucinas 1 y 6 (IL-1, IL-6) y factor de necrosis tumoral (TNF), que actúan sobre células residentes del mismo. El sistema inmune innato desempeña un papel importante en el inicio y progresión de la enfermedad, mediante la identificación de patrones moleculares asociados con patógenos y daño, que modulan las funciones efectoras y reguladoras de las células donde se expresan, para dirigir la respuesta inmune específica. Las células Th17 favorecen la disrupción de la barrera hematoencefálica, que permite la migración de leucocitos al sistema nervioso central y desencadena la cascada de la inflamación; el perfil Th1 (IL-1, IL-6) colabora para perpetuarla. La función de las células $B$ es la producción de anticuerpos y citocinas (IL-6, IL-12 y TFN). Conocer la fisiopatología de la esclerosis múltiple permitirá desarrollar nuevas opciones terapéuticas que impacten en la historia natural de la enfermedad y su pronóstico.
\end{abstract}

PALABRAS CLAVE: Esclerosis múltiple. Citocinas. Inmunidad innata. Imunidad humoral.

\begin{abstract}
Multiple sclerosis is a demyelinating inflammatory disease that affects the central nervous system. Its etiology is the result of a complex interaction between genetic and environmental factors that trigger a deregulated immune response, with the resulting inflammation and neuronal/axonal degeneration. Neuroinflammation is triggered when peripheral leukocytes migrate to the central nervous system and release cytokines such as interleukins 1 and 6 (IL-1 and 6) and tumor necrosis factor (TNF), which act on dwelling cells. The innate immune system plays an important role in the onset and progression of the disease by identifying molecular patterns associated with pathogens and damage, which modulate effector and regulatory functions of the cells where they are expressed, in order to direct the specific immune response. Th17 cells favor the disruption of the blood-brain barrier, which enables the migration of leukocytes to the central nervous system and the triggering of the inflammatory cascade; the Th1 profile (IL-1, IL-6) collaborates to perpetuate it. B-cell function is to produce antibodies and cytokines (IL-6, IL-12 and TFN). Knowledge on multiple sclerosis pathophysiology will enable the development of new therapeutic options that impact on natural history of the disease and its prognosis.
\end{abstract}

KEY WORDS: Multiple sclerosis. Cytokines. Innate immunity. Humoral immunity.

Correspondencia:

Carlos Fredy Cuevas-García

E-mail: cacu61152@ hotmail.com
Fecha de recepción: 12-04-2017

Fecha de aceptación: 08-01-2018

DOI: 10.24875/GMM.18003407
Gac Med Mex. 2018;154:588-597

Disponible en PubMed

www.gacetamedicademexico.com 


\section{Introducción}

La esclerosis múltiple (EM) es un trastorno inflamatorio crónico autoinmune mediado predominantemente por células $T$, que inducen desmielinización multifocal y gliosis con pérdida de oligodendrocitos y axones. Es el resultado de la compleja interacción entre la susceptibilidad genética y factores ambientales como la infección crónica por el virus de Epistein-Barr (VEB), el tabaquismo y la deficiencia de la vitamina $\mathrm{D}$.

La fisiopatología está determinada por el daño a la vaina de mielina que rodea y protege a los axones del sistema nervioso central inducido por células $T$ autorreactivas. Modelos murinos muestran que la encefalomielitis autoinmune experimental (EAE) puede desencadenarse mediante la transferencia de células $T$ autorreactivas de mielina, con la consiguiente neuroinflamación y desmielinización.

Durante las dos últimas décadas, los avances en la inmunología han permitido conocer más acerca de la inmunidad humoral e innata, la desregulación de citocinas y el perfil efector de las células Th17, propiamente los cambios epigenéticos promueven el fenotipo inflamatorio y la desmielinización, sin embargo, aún queda en duda cómo actúan sobre la disfunción mitocondrial, el estrés oxidativo y la degeneración axonal.

\section{Epigenética de la esclerosis múltiple}

La epigenética estudia los cambios del ADN que influyen en la expresión génica sin alterar la secuencia de ADN, producto de factores ambientales. La metilación del ADN, la modificación de las histonas y el silenciamiento de los miARN son los tres mecanismos epigenéticos más importantes. ${ }^{1}$

La metilación del ADN consiste en la unión de un grupo metilo a un residuo de citosina en la cadena de nucleótidos del ADN, que produce dinucleótidos citosina-guanina $(\mathrm{CpG}$ ) que se agrupan en el genoma constituyendo las llamadas islas $\mathrm{CpG}$, proceso llevado a cabo por las enzimas ADN metiltransferasas (DNMT). La metilación de residuos de citosina silencia los genes, posiblemente bloqueando la unión de factores transcripcionales, en consecuencia, la hipometilación del ADN promueve la transcripción.

La modificación de histonas es otro mecanismo epigenético que consiste en la acetilación y desacetilación en residuos de lisina, llevados a cabo por la histona acetiltransferasas (HAT) e histona deacetilasas (HDAC), respectivamente. La acetilación de las histonas facilita la unión de los factores transcripcionales al ADN, la desacetilación, que inhibe la transcripción, influyendo en el proceso inflamatorio.

Los cambios epigenéticos pueden generarse también a nivel postranscripcional mediante microARN (miARN), ARN no codificantes de una sola cadena que modulan la diferenciación celular, la proliferación y la apoptosis; su desregulación se ha asociado con autoinmunidad e inflamación. ${ }^{2}$

Algunos factores de riesgo identificados en el desarrollo de EM son las infecciones virales, especialmente por el VEB, el sexo femenino, la deficiencia de vitamina $D$, el tabaquismo y el antecedente familiar de EM.

La susceptibilidad genética más importante se relaciona con los genes del complejo mayor de histocompatibilidad, específicamente el haplotipo HLADRB1*1501, que con mayor frecuencia es transmitido por las madres y podría estar mediado por mecanismos epigenéticos como la metilación del ADN y la desacetilación de las histonas. ${ }^{3}$

EI VEB genera infección viral latente crónica en los linfocitos y sobrerregula la DNMT, influyendo en la proliferación celular y la estabilidad del genoma, no obstante, únicamente su antígeno extraíble presenta asociación con la aparición de la EM. ${ }^{4}$

La vitamina $D$ inhibe el locus de la IL-17 mediante modificación de la histona deacetilasa 2 (HDAC2) en la región promotora de la IL-17A, en consecuencia, su deficiencia favorece el perfil Th17. ${ }^{4}$

El tabaquismo se ha relacionado con el aumento de las recaídas y el número de lesiones cerebrales activas en la RM. Altera la modificación de las histonas, el patrón de metilación del ADN y la expresión del miARN. Además, activa neutrófilos, macrófagos y monocitos. $^{5}$

\section{Inmunopatología}

La presencia de los factores epigenéticos descritos no es suficiente para explicar la fisiopatología de la EM, en la que predominan los fenotipos inflamatorios Th1 y Th17, quedando aún por conocer cuáles son los mecanismos específicos que desencadenan la inflamación.

La mayoría de los estudios sobre la regulación epigenética de citocinas se ha centrado en la diferenciación del perfil Th17, donde se demuestra que las regiones promotoras de los genes de IL-17 experimentan acetilación de las histonas e hipermetilación del ADN. 


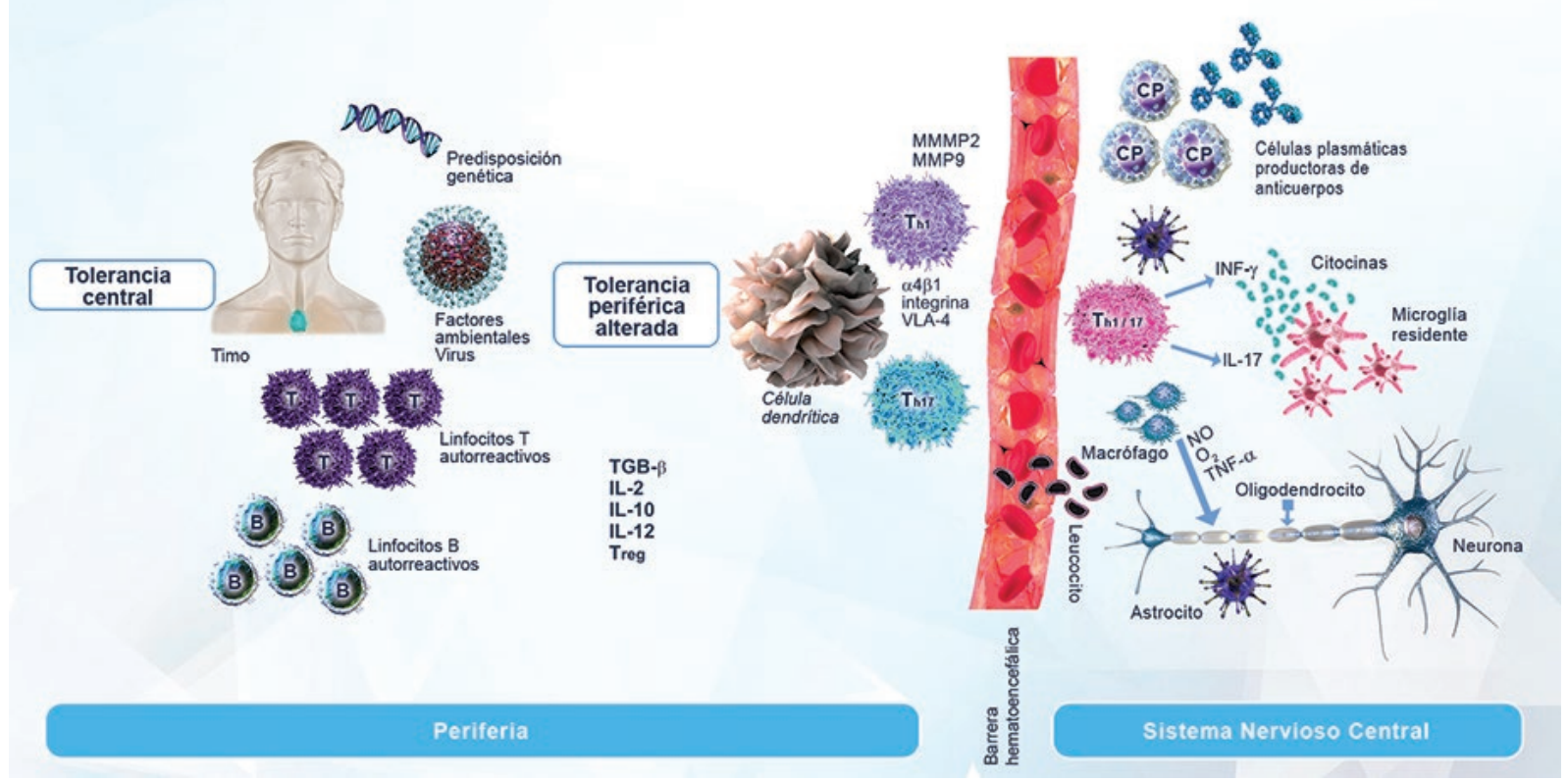

Figura 1. Fisiopatología de la esclerosis múltiple. Los linfocitos $T$ naïve que escapan de la tolerancia periférica, son reclutados y activados por autoantígenos, para ser mostrados a las células presentadoras de antígenos. En presencia de un microambiente favorecedor (factores genéticos, hormonales, infecciones, inmunodeficiencias), aumentará la proliferación de linfocitos autorreactivos que producen anticuerpos 0 activan células $T$ citotóxicas antígeno específicas. Si los mecanismos de tolerancia periférica no son capaces de controlar los linfocitos $T$ autorreactivos a través de células supresoras como $T_{\text {reg }}$, se manifestará clínicamente una enfermedad autoinmune. En el contexto de EM, las células dendríticas inician y dirigen a las respuestas inmunes innatas y adaptativas que promueven el desarrollo de células efectoras Th17 y Th1 productoras de citocinas que actuarán sobre células residentes del SNC, que desencadenarán neuroinflamación. $T_{\text {reg }}=$ regulatory $T$ cell, $I L=$ interlucina, TGF- $\beta=$ transforming growth factor beta, STAT = signal transducer and activator of transcription, TNF- $\alpha=$ tumour necrosis factor alpha, IFN = interferon, VLA-4 = very late antigen-4, MMP2 = matrix metalloproteinase-2; MMP9 = matrix metalloproteinase-9.

Otro mecanismo mediante el cual se modulan las respuestas de las células $T$ es la regulación génica mediada por miARN. Los niveles de expresión miR155 y miR-326 están estrechamente relacionados con la diferenciación de células TCD4 hacia el fenotipo Th17., ${ }^{5,6}$

Los procesos de metilación del ADN y la modificación de las histonas son teóricamente susceptibles de tratamiento, dirigiéndose a las enzimas implicadas en estos procesos, por ejemplo, los inhibidores de deacetilasa, no obstante, son inespecíficos ya que los cambios epigenéticos son específicos de órgano, por lo tanto, el tratamiento actual de la EM continúa dirigido a controlar el proceso inflamatorio.?

A continuación, se explicará brevemente la función de los componentes más importantes de la inmunidad innata y adaptativa en la inflamación de la EM.

\section{La neuroinflamación y la compleja red de citocinas}

Las enfermedades neuroinflamatorias como EM se presentan cuando los leucocitos periféricos migran al sistema nervioso central (SNC) y liberan citocinas como IL-1, IL-6 y TNF, que actúan sobre células residentes del SNC (por ejemplo, microglía) para producir más citocinas y perpetuar la inflamación (Figura 1).

Las citocinas son proteínas que regulan el comportamiento de las células. Específicamente en EM favorecen el perfil efector Th1 o Th17, provocando inflamación, daño tisular y deterioro neurológico.

Las citocinas más importantes hasta el momento en la fisiopatología de la EM son las siguientes:

1) IL-23, producida por células presentadoras de antígeno (CPA) en tejidos linfoides secundarios y la microglía. Su función es generar y estabilizar un fenotipo Th efector específico y estimular la producción de IL-17A, IL-17F, IL-22 y factor estimulante de colonias de granulocitos-macrófagos (GM-CSF). ${ }^{8,9}$

2) IL-17 actúa sobre células estromales y endoteliales, astrocitos y microglía. Destruye la integridad de la barrera hematoencefálica $(\mathrm{BHE})$, permitiendo la migración de leucocitos al SNC y desencadenar el proceso inflamatorio. Los astrocitos responden a la IL-17 mediante la producción de quimiocinas que atraen neutrófilos; estos colaboran activamente con el daño tisular. ${ }^{10}$ Los ratones que carecen del gen de IL-17A (ratones IL17a -/-) son susceptibles a la $E A E$, sin embargo, desarrollan una enfermedad 
Tabla 1. Funciones del IFN- $\gamma$ y TNF en esclerosis múltiple

\begin{tabular}{|c|c|}
\hline IFN- $\gamma$ & TNF \\
\hline Producido por los linfocitos. & Producido por células mieloides, linfocitos. \\
\hline Inhibe a la IL-17. & Induce apoptosis de los oligodendrocitos. \\
\hline $\begin{array}{l}\text { Favorece la integridad de la BHE, mediante la expresión de } \\
\text { proteínas de unión en las células endoteliales. }\end{array}$ & Disminuye la absorción de glutamato por los astrocitos. \\
\hline Promueve la fagocitosis de desechos de mielina por CPA. & $\begin{array}{l}\text { Estimula la expresión de moléculas de adhesión en células } \\
\text { endoteliales y astrocitos (extravasación de células T a través de la } \\
\text { BHE y parénquima cerebral). }\end{array}$ \\
\hline $\begin{array}{l}\text { Impide la acumulación de productos neurotóxicos (al promover la } \\
\text { fagocitosis). }\end{array}$ & $\begin{array}{l}\text { Sinérgicamente con IFN- } \gamma \text { promueven la expresión de moléculas } \\
\text { de MHC sobre astrocitos y oligodendrocitos, que magnifica la } \\
\text { citotoxicidad de TCD8+. }\end{array}$ \\
\hline
\end{tabular}

retardada, corroborado la importancia de esta citocina en la fisiopatología. 11,12

3) IL-6 es crucial para el desarrollo de EAE. Bloquea la expresión de FOXP3 de las células Th efectoras, impidiendo su función reguladora. Favorece la expresión del receptor de la IL-1 sobre las células T para estabilizar el perfil Th1 local y contrarrestar la tendencia natural a la resolución de la neuroinflamación. ${ }^{13}$ La expresión ininterrumpida de estas citocinas y la llegada continua de leucocitos al SNC perpetúan la inflamación.

4) El interferón gamma (IFN- $\gamma$ ) era central en la fisiopatología de EM hasta hace un par de décadas; actualmente es difícil definir su papel ya que actúa sobre muchos tipos celulares y tiene propiedades pro y antiinflamatorias que parecen depender del microambiente, de la dosis y del momento específico de la exposición (Tabla 1). En EM ejerce un efecto predominantemente inhibitorio en el SNC y excitatorio en la médula espinal. ${ }^{14} \mathrm{La}$ inyección de IFN- $\gamma$ directamente en el SNC desencadenó inflamación en modelos murinos,,$^{15}$ pero la administración de anticuerpos bloqueadores y la carencia de genes que lo codificaran exacerbaron la $\mathrm{EAE},{ }^{16}$ sugiriendo también un papel protector sobre la neuroinflamación.

5) El tumor necrosis factor (TNF) es producido por macrófagos, células TCD4 y TCD8 entre otras, posee funciones pro y antiinflamatorias (Tabla 1). Su bloqueo en pacientes con EM dio lugar a recaídas más frecuentes y graves. ${ }^{17} \mathrm{La}$ causa probablemente fue la diversidad de receptores a los que puede unirse.

6) EI GM-CSF es una citocina producida por células $T$ en respuesta a la IL-23 y se ha asociado con funciones neurodegenerativas de la microglía.

\section{Tabla 2. Funciones de TGF- $\beta$}

Inhibe la producción de IL-2, IL-12 (Th1).

Disminuye la producción de IFN- $\gamma$, como consecuencia del bloqueo Th1.

Promueve la diferenciación de $\mathrm{T}_{\text {reg }}$.

Activa células TCD8 ${ }^{+}$.

Favorece el perfil Th9.

TGF- $\beta$ = factor de crecimiento transformante beta.

Representa el medio de comunicación entre los linfocitos $T$ y las células mieloides reclutadas en respuesta a GMCSF, estas últimas son relevantes para el SNC porque fagocitan e inducen apoptosis mediada por receptores y son la fuente principal de especies reactivas de oxígeno. ${ }^{18}$

7) Transforming growth factor beta (TGF- $\beta$ ) es una citocina que tiene tres isoformas y la expresión de cada una es espacial y temporalmente distinta. El TGF- $\beta 1$ está presente en el sistema inmune y tanto el TGF- $\beta 2$ como el TGF- $\beta 3$ se expresan en neuronas y la glía; la infiltración por células Th1 en el SNC en los pacientes con EM está parcialmente regulada por las funciones de TGF- $\beta$ (Tabla 2). ${ }^{19}$

El interés en el TGF- $\beta$ dentro de la fisiopatología de la EM ha aumentado posterior a la observación de que IL-6 + TGF- $\beta$ impulsa la diferenciación de células murinas Th17 in vitro, aun en ausencia del factor de transcripción T-beta, que regula el perfil Th1 y Th17.19,20

En condiciones normales, la presencia de TGF- $\beta$ en los ganglios linfáticos donde los linfocitos $T$ naïve encuentran típicamente al antígeno, suprime la activación y diferenciación de las células $T$, incluso en presencia de citocinas promotoras de Th1, como IL-12.

En zonas de inflamación del SNC de pacientes con EM puede aumentar la producción de citocinas Th1, al mismo tiempo que favorece la expresión de IL-10, que contrarresta la actividad de las células Th1 efectoras contra la mielina. ${ }^{21}$ 
La ausencia de señalización de TGF- $\beta 1$ resulta en la diferenciación de células T espontáneas y autoinmunidad. ${ }^{22,23}$ El TGF- $\beta$ induce el perfil Th9, asociado con la regulación negativa de las células Th17. ${ }^{24}$

8) La IL-9 en el LCR en pacientes con EM se correlaciona negativamente con la inflamación, la neurodegeneración y la progresión de la enfermedad, apoyando su papel regulador. ${ }^{25}$ In vitro, la proliferación de células precursoras de oligodendrocitos es promovida por el perfil Th9 junto con IFN- $\gamma$, pero se inhibe en presencia de IL-17. ${ }^{26}$

\section{Inmunidad innata}

El sistema inmune innato desempeña un papel importante en el inicio y progresión de la enfermedad, mediante la modulación de las funciones efectoras de células $T$ y $B$; nos enfocaremos exclusivamente a los receptores de reconocimiento de patrones tipo Toll (TLR), autofagia, inflamasomas y células natural killer (NK).

\section{TLR}

Los TLR son glicoproteínas transmembrana que se expresan en las células mieloides, CPA, linfocitos T y $B$. Pueden unirse a una amplia gama de ligandos microbianos y a patrones moleculares asociados con daño (DAMP) endógenos o alarminas como HSP70 (Heat Shock Proteins 70) y HMGB1 (high-mobility group protein 1), producidos como resultado de daño tisular o muerte celular.

Además de la identificación de patrones moleculares asociados con patógenos (PAM) y DAM, su función es modular las funciones efectoras y reguladoras de las células donde se expresan, es decir, representan un punto de unión entre la inmunidad innata y la adaptativa.

En EM, el más estudiado es el TLR2, identificado en células endoteliales, microglía, astrocitos y oligodendrocitos; se presenta como un homodímero o heterodímero asociado con TLR1 o TLR6. ${ }^{27}$ TLR2 estimula la producción de IL-1, IL-6, IL-12 e IL-23, favoreciendo el perfil Th1 y Th17; conjuntamente influye sobre la función de células $T$ reguladoras $\left(T_{\text {reg }}\right) .{ }^{28}$

En el SNC puede contribuir a la neuroinflamación mediante una vía PARP-1 dependiente. ${ }^{29}$

El TLR2 es estimulado por agentes infecciosos (patógenos o comensales) que, en caso de no limitarse, provocará disminución de células $T_{\text {reg }}$ y escape de células $\mathrm{T}$ autorreactivas preexistentes. La producción de
IL-1 e IL-6 como resultado del estímulo inhibirá la diferenciación de las células $\mathrm{T}_{\text {reg }}$ inducibles ( $\mathrm{iT}_{\text {reg }}$ ), importantes para la tolerancia periférica, contribuyendo al defecto de células $T_{\text {reg, }}$, conocido en pacientes con EM..$^{30,31}$

Los TLR desempeñan un papel importante en la regulación de la autoinmunidad atribuible a la identificación de PPR (receptores de reconocimiento de patrones) y DAM, estos son capaces de desencadenar una respuesta inflamatoria en ausencia de estímulo infeccioso.

\section{Autofagia}

Es una vía de degradación dependiente de lisosomas que elimina organelos innecesarios y proteínas para el reciclaje de energía. Hay tres subtipos de autofagia: la macrofagia, la autofagia mediada por chaperonas y la mitofagia, esta última responsable de la degradación de mitocondrias disfuncionales.

La autofagia mantiene la homeostasis de las mitocondrias mediante la disminución de especies reactivas de oxígeno, importantes en la neuroinflamación. ${ }^{32}$ El bloqueo o disfunción de la autofagia provoca la activación de inflamasomas y neurodegeneración.

\section{Inflamasomas}

Son proteínas que forman complejos de señalización sensibles al daño y al estrés, influyen sobre la producción de las citocinas IL-1 $1 \beta$ e IL-18 mediante la activación de la caspasa-1 y la piroptosis. No poseen una secuencia de señalización para su secreción y se producen a partir de en una forma inactiva, la proIL-1 $\beta$ y la pro-IL-18. El inflamasoma NLRP3 —el más estudiado- promueve la migración de leucocitos al SNC en la EAE. ${ }^{33}$ Se ha identificado caspasa- 1 e IL-1 $\beta$ en placas de pacientes con $\mathrm{EM}^{34}$ y se ha propuesto que los niveles de IL-1 $\beta$ en el LCR pueden ser utilizados como predictores de la respuesta in situ al tratamiento, gravedad y progresión de la enfermedad. ${ }^{35}$ Farmacológicamente, el IFN- $\beta$ disminuye la expresión de NLRP $3^{36}$ y los niveles plasmáticos de IL-1 $\beta$ en pacientes con EM. ${ }^{37}$

No obstante, aun cuando existen tratamientos de primera línea para la EM, su uso no es exitoso en todos los pacientes. Existe una dependencia de sus efectos a NLRP3 y esta característica divide a los pacientes en respondedores y no respondedores a IFN- $\beta .^{38}$ 
Los primeros muestran niveles disminuidos de NLRP3 e IL-1 $\beta$ antes del tratamiento, mientras que los no respondedores muestran sobrerregulación tres meses después del tratamiento con IFN- $\beta .^{38,39} \mathrm{La}$ EAE independiente de NLRP3 es resistente a IFN- $\beta$ y muestra mínima remisión debido a daño neuronal irreversible.

\section{Células natural killer}

Las células NK son parte de la inmunidad innata y comprenden una subpoblación de linfocitos que fenotípicamente expresan CD16 o CD56 en su superficie, en ausencia de CD3. Las subpoblaciones de NK son las siguientes: CD56 bright, CD56 dim CD16-, CD56 dim CD16+ y CD56-.

Las células NK CD56 bright deben su nombre a la expresión de CD56 sobre su superficie (también conocida como molécula de adhesión de células neurales), expresan el receptor inhibidor NKG2A y representan solo $10 \%$ de las células NK.

Las CPA modulan a las células NK mediante receptores para IL-12, IL-15 e IL-18 que conducen a la liberación de moléculas como IFN- $\gamma$, IL-10 e IL-13, TNF- $\beta$ y GM-CSF; su función reguladora se relaciona con la liberación de estas citocinas. ${ }^{40}$

La citotoxicidad de las células NK puede atenuar la inflamación en la fase aguda mediante la muerte de células T y microglía, pero perjudicando la reparación durante la etapa tardía a través de la muerte de células troncales neurales. La liberación de interferón y la citotoxicidad natural por células NK es crucial para la defensa innata frente a los virus. Los estudios epidemiológicos sugieren que los herpesvirus están relacionados con el desarrollo de EM, específicamente el VEB. ${ }^{41}$

A diferencia de este, se ha sugerido que el citomegalovirus (CVM) protege del desarrollo de EM, los resultados son contradictorios y probablemente dependan de la compleja interacción huésped-patógeno. La infección por CMV induce una reconfiguración adaptativa de las células NK en adultos sanos, a través de la expansión del subconjunto NKG2 ${ }^{\text {bright. }}$. En pacientes con EM y seropositividad para CMV, la expresión de NKG2C se asoció con menor riesgo de progresión de la enfermedad, sugiriendo que esta puede ser beneficiosa, sin embargo, es incierto si las células NKG2C pueden explicar por completo el supuesto papel protector de CMV en EM. ${ }^{42}$

Algunos fármacos se han beneficiado de las funciones reguladoras de las células NK.
La citotoxicidad dependiente de anticuerpos por células NK CD56 dim es un mecanismo terapéutico esencial en la supresión de células $T$ y $B$ mediada por alemtuzumab. ${ }^{43}$ El natalizumab aumenta el número células NK totales y NK CD56 ${ }^{\text {bright }}$ periféricas con un número reducido de células NK en el LCR. ${ }^{44}$ Por otra parte, daclizumab mejora los mecanismos endógenos de tolerancia inmunológica, reduciendo la activación temprana de las células $T$ mediante el bloqueo del receptor de IL-2 que permite la expansión del fenotipo CD56 bright. También favorece que las células NK, tras su unión con el receptor de la IL-2 de los linfocitos T, controlen la muerte directa, que para los CD56 bright involucra la liberación de granzima. ${ }^{45-47}$

\section{Inmunidad celular, ¿autorreactividad o regulación?}

\section{Th1 versus Th17}

Durante décadas, la observación de que las células T específicas de mielina de pacientes con EM expresaban el perfil Th1 dio validez a su papel predominante en la fisiopatología de la enfermedad. ${ }^{48}$

El hallazgo de la expresión incrementada de IL-17 en sangre periférica, LCR y en las lesiones del SNC en pacientes con EM, asociado con el papel controversial del IFN- $\gamma$ y TNF- $\alpha$ le han proporcionado mayor relevancia. ${ }^{49-51}$

Las células Th1 en sangre periférica y LCR son 10 veces más altas que las Th17, sin embargo, estas últimas tienen un aumento significativo durante las recaídas, lo cual no se ha observado con Th1. ${ }^{52}$

La IL-17 actúa sobre células endoteliales, epiteliales, mieloides y fibroblastos. Potencializa la secreción de IL-8, CXCL1, CXCL6, IL-1 $\beta$, IL-6, TNF- $\alpha$, MIP-2 (proteína inflamatoria del macrófago 2), MCP-1 (proteína quimioatrayente de monocitos 1) y GMCS, este último un potente inductor de la migración de neutrófilos $^{53}$ (Figura 2).

La IL-23 estimula la expresión de IL-17 en células TCD4 de memoria, capaces de coexpresar IFN- $\gamma$ (Th1). Ambas células, tanto Th1 como Th17, cruzan la BHE, sin embargo, las células TCD4 IFN- $\gamma^{+} \mathrm{IL}-17^{+}$en pacientes con EM parecen cruzarla más eficientemente, es decir, son más encefalitogénicas. ${ }^{54}$

Los datos anteriores sugieren que tendría sentido neutralizar la subunidad p40, compartida por IL-12 (inductora de Th1) y IL-23, lo que bloquearía ambos perfiles. Sin embargo, este bloqueo demostró en dos ensayos clínicos (briakinumab/ustekinumab) que sus 


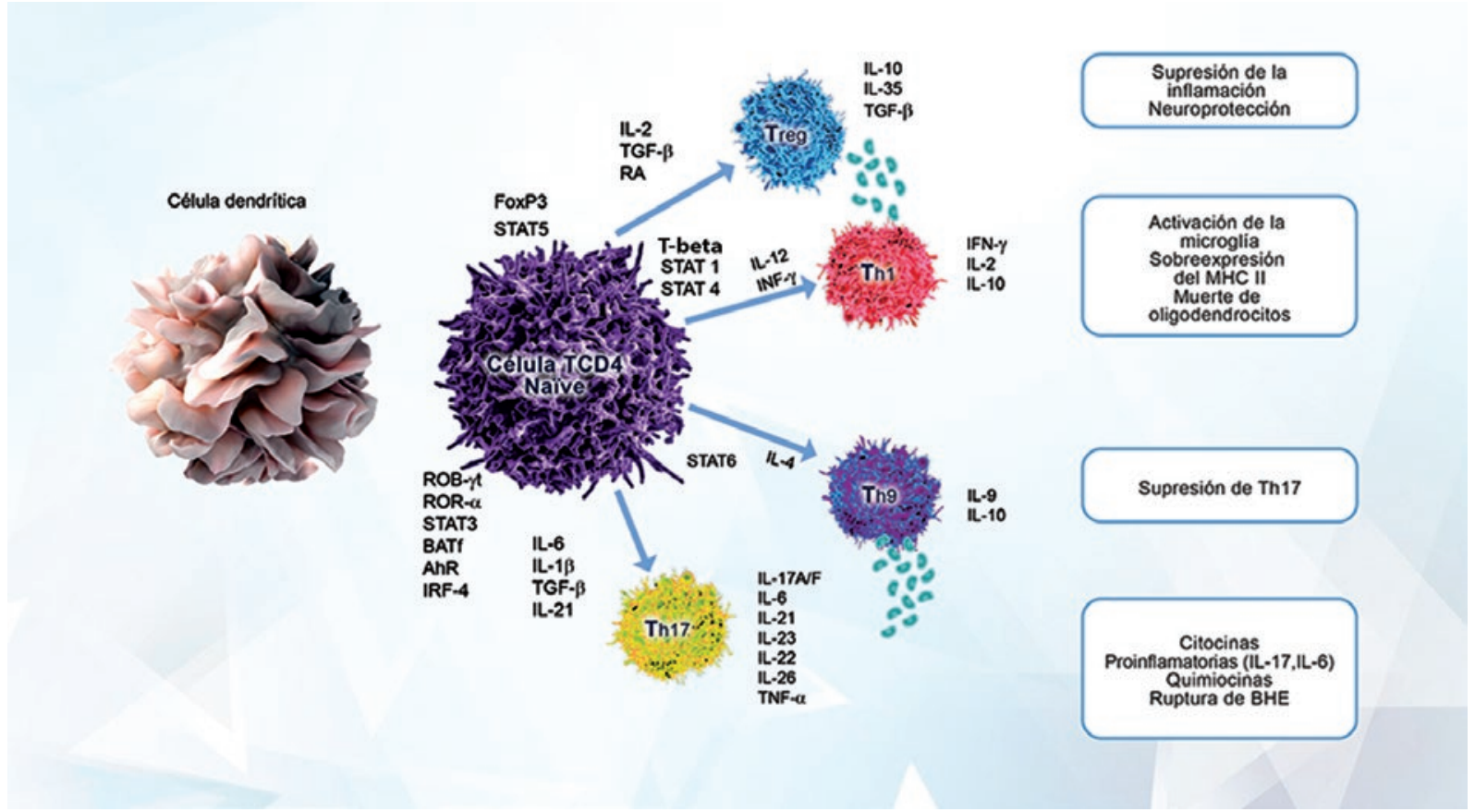

Figura 2. Perfiles efectores de células TCD4 en EM. La diferenciación de precursores de linfocitos TCD4 + naïve a varios linajes de células TCD4+ se controla a través de factores de transcripción específicos y citocinas estimuladoras e inhibidoras, su desequilibrio puede conducir a autoinmunidad. Las células dendríticas representan un punto fundamental en el desarrollo de tolerancia inmunológica. Promueven respuestas efectoras y supresoras, tal sucede con el perfil Th9 y $T_{\text {reg. }}$. Las células dendríticas tolerogénicas podrían ser una alternativa terapéutica en el tratamiento de enfermedades autoinmunes, como EM. $T_{\text {reg }}=$ regulatory $T$ cell, IL = interlucina, TGF- $\beta=$ transforming growth factor-beta, FoxP $3=$ fork head box protein $P 3, S T A T=$ signal transducer and activator of transcription, $R A=$ retinoic acid, TNF = tumour necrosis factor, AhR = aryl hydrocarbon receptor, $I R F=$ interferon regulatory factor, IFN = interferon, $L T=$ lymphotoxin, $M H C=$ major histocompatibility complex, $B H E=$ barrera hematoencefálica.

efectos no fueron suficientes para justificarlos como monoterapia de primera línea. ${ }^{55,56}$

Estos resultados pueden deberse en parte a que el bloqueo de IL-12 puede inhibir la función protectora mediada por IFN- $\gamma$ en etapas tempranas de la enfermedad. El IFN- $\beta$ puede inhibir Th17 como parte de sus efectos sobre la mejoría clínica, reforzando la importancia del perfil. 57,58

Por motivos desconocidos, algunos pacientes tienen un perfil dominante, Th1 o Th17, que no solo impactará en el tratamiento sino en la localización de las lesiones, un cociente Th17/Th1, con predominio del primero se caracterizará por infiltración TCD4 y macrófagos en todo el cerebro, mientras que el predominio del perfil Th1 produce lesiones localizadas. ${ }^{59}$

El papel de Th1 y Th17 aún no se comprende por completo, probablemente existan citocinas y factores de trascripción aún no definidos que actúan sinérgicamente en la fisiopatología, por ahora el papel que desempeñan en la neuroinflamación sigue siendo esencial.

\section{Células $T_{\text {reg }}$}

Mantener las células autorreactivas bajo control para prevenir la autoinmunidad es tarea de las células llamadas "reguladoras", de las cuales la mejor caracterizada, pero no única, es la célula $T_{\text {reg }}$, inducida principalmente por TGF- $\beta$.

Las células $T_{\text {reg }}$ expresan los marcadores CD4+CD25+FoxP3+y representan $5 \%$ de la población total de células TCD4+, su función es controlar la expresión de células $T$, mediante la internalización del receptor de la IL-2.

Las células $T_{\text {reg }}$ están disfuncionales en pacientes con EM debido a un repertorio TCR restringido que les confiere ser inherentemente propensas a la autoinmunidad por falta de diversidad en su población. . $^{60,61}$

Adicionalmente, la señalización de TGF- $\beta$ es más baja en los linfocitos TCD4 ${ }^{+}$de pacientes con EM, provocando que estas células sean menos sensibles a TGF- $\beta$; en parte esto explicaría por qué las terapias dirigidas a este blanco han fracasado. ${ }^{62}$

Es importante remarcar que el TGF $\beta$ y la vía de señalización del receptor de hidrocarburos de arilo (AhR) pueden inducir $\mathrm{T}_{\text {reg }}$ o Th17 dependiendo del microambiente y factores inflamatorios como ligandos de TLR2, IL-6, IFN- $\gamma$, esto es trascendental al considerar una terapia inductora de $T_{\text {reg, }}$, ya que existe la posibilidad de inducir Th17. 
Por último, los glucocorticoides pueden aumentar transitoriamente la expresión FOXP3, favoreciendo la inmunoregulación. ${ }^{63}$

\section{Células TCD8+}

La base inmunológica de la EM y su modelo experimental, la $E A E$, se han centrado en gran medida en las células $\mathrm{TCD} 4^{+}$como mediadoras y reguladoras de la enfermedad. La inducción de la enfermedad mediante la transferencia adoptiva de células TCD4+ específicas de mielina favoreció el desconocimiento de una posible contribución en la fisiopatología de las células TCD8+. Estas representan la población de células $T$ predominantes en las lesiones de EM.

Las TCD8+ expresan CD161 y el receptor de quimiocina 6 (CCR6), mediante el cual penetran al SNC a través de la unión a la $\alpha 4$-integrina. Producen mediadores proinflamatorios como la IL-17 y su presencia en el cerebro y LCR se ha correlacionado con daño axonal agudo. Las funciones efectoras más conocidas incluyen mecanismos de citotoxicidad directa a oligodendrocitos, muerte neuronal, desmielinización y producción de citocinas inflamatorias.

Sus funciones protectoras dependen de la producción de IFN- $\gamma$ y perforina a través de citotoxicidad directa sobre células TCD4+ autorreactivas, modulación de citocinas proinflamatorias, inhibición de CPA y producción de IL-10.64

En pacientes con EM, los niveles y su función en sangre periférica se encuentran disminuidas y se han relacionado con actividad supresora sobre TCD4+ específicas de la mielina. ${ }^{65,66}$ Sus funciones pueden ser inducidas terapéuticamente con el acetato de glatiramer. A diferencia de las células TCD8 ${ }^{+}$específicas del SNC, las inducidas farmacológicamente están restringidas a la molécula HLA-E. En sangre periférica, esto queda demostrado con la inversión del cociente CD4/ CD8, como resultado del aumento de TCD8 ${ }^{+}$a las 12 horas de administrado el fármaco. ${ }^{67}$

El tratamiento con metilprednisolona conduce a aumento significativo de $\mathrm{TCD} 8^{+}{ }_{\text {reg }}$ en sangre periférica de pacientes con EM, lo que sugiere que la recuperación de la recaída bajo tratamiento con glucocorticoides podría estar mediada, en parte, por la función reguladora de las estas células. ${ }^{68}$ Aunque su papel sigue siendo controversial, actualmente existe una amplia evidencia de su función reguladora, apoyada en hallazgos de pérdida de dicha función durante las recaídas de la EM y su restauración durante la mejoría; el papel que desempeña en la modulación final de la EM será de gran interés en el futuro.

\section{Inmunidad humoral}

\section{Células B}

Durante décadas, su papel en EM estuvo restringido a la producción de anticuerpos y en este momento no queda duda que son importantes en la fisiopatología de la enfermedad, ya que se encuentran elevadas en lesiones del SNC y LCR y conjuntamente muestran expansión clonal e hipermutación, como reflejo de su activación. Son responsables de la producción de bandas oligoclonales y su bloqueo mediante anticuerpos antiCD20 como rituximab y ocrelizumab ha demostrado efectos benéficos. ${ }^{69}$

Los autoantígenos sugeridos como dianas de estos anticuerpos permanecen desconocidos, por lo tanto, los mecanismos que controlan la activación, selección y maduración de las células $B$ siguen siendo especulación.

La siguiente interrogante es, ¿cómo migran al SNC? El mecanismo está influido por la gran cantidad de receptores que expresan, entre ellos CXCL13, una quimiocina correlacionada con la conversión del síndrome clínicamente aislado a EM y que facilita su reclutamiento al SNC.70

En comparación con las células $\mathrm{T}$, la infiltración por células B en el SNC varía en el trascurso de la enfermedad. Las meninges de los pacientes con enfermedad progresiva secundaria a menudo contienen estructuras linfoides terciarias con células plasmáticas, células $B$, células $T$ y células dendríticas foliculares, producto de la inflamación crónica. ${ }^{71}$

Su función efectora facilita la desmielinización, mediante la citotoxicidad celular dependiente de anticuerpos, donde las células del sistema inmune innato como las NK reconocen y se unen al complejo antígeno-anticuerpo a través del receptor Fc-gamma, desencadenando citotoxicidad y lisis; otros mecanismos descritos son la opsonización, fagocitosis y activación del complemento. ${ }^{72}$

Los anticuerpos monoclonales CD20 como rituximab u ocrelizumab han mostrado ser eficaces para reducir las tasas de recaída. Estos fármacos agotan subconjuntos de células $B$ pero no plasmáticas, de modo que sus contribuciones radican en su capacidad para modular la presentación de antígenos y producción de IL-6. ${ }^{73,74}$ 
Las células B producen citocinas como la IL-6, que activan a la microglía y son responsables de la pérdida de la densidad dendrítica en las placas corticales. También muestran un perfil regulador mediante la producción de IL-10 y pueden actuar como CPA.

El papel de las células $B$ en la patología de la EM no está limitado a la producción de anticuerpos, por lo que queda por conocer su función sobre la inducción, recaídas o progresión de la enfermedad.

\section{Conclusiones}

Pese a los grandes avances en la fisiopatología de la EM, quedan muchas interrogantes por responder. Posiblemente los futuros hallazgos en la epigenética y la inmunidad innata permitan regular la respuesta inmune antes de la liberación de células $T$ autorreactivas y formación de anticuerpos. Los blancos terapéuticos deberán considerar la compleja interacción del sistema inmune, ser altamente específicos y preservar o favorecer la inmunorregulación.

\section{Bibliografía}

1. Van-Den-Elsen PJ, Van-Eggermond MC, Puentes F, Van-Der-Valk $P$ Baker D, Amor S. The epigenetics of multiple sclerosis and other related disorders. Mult Scler Relat Disord. 2014;3(2):163-175.

2. Huang $Q$, Xiao B, Ma X, Qu M, Li Y, Nagarkatti $P$, et al. MicroRNAs associated with the pathogenesis of multiple sclerosis. J Neuroimmunol. 2016;295-296:148-161.

3. Ebers G. Interactions of environment and genes in multiple sclerosis. Lancet Neurol. 2008;7:268-277.

4. Küçükali Ci, Kürtüncü M, Çoban A, Çebi M, Tüzün E. Epigenetics of multiple sclerosis: an updated review. Neuromolecular Med. 2015;17:83-96.

5. Koch MW, Metz LM, Kovalchuk O. Epigenetics and miRNAs in the diagnosis and treatment of multiple sclerosis. Trends Mol Med. 2013;19:23-30

6. Pistono C, Osera C, Boiocchi C, Mallucci G, Cuccia M, Bergamaschi R, et al. What's new about oral treatments in multiple sclerosis? Immunogenetics still under question. Pharmacol Res. 2017;120:279-293.

7. Peedicayil J. Epigenetic drugs for multiple sclerosis. Curr Neuropharmacol. 2016:14:3-9.

8. Langrish CL, Chen Y, Blumenschein WM, Mattson J, Basham B, Sedgwick JD, et al. IL-23 drives a pathogenic $T$ cell population that induces autoimmune inflammation. J Exp Med. 2005;201:233-240

9. Cua DJ, Sherlock J, Chen Y, Murphy C a, Joyce B, Seymour B, et al. Interleukin-23 rather than interleukin-12 is the critical cytokine for autoimmune inflammation of the brain. Nature. 2003;421:744-748

10. Simmons SB, Liggitt D, Goverman JM. Cytokine-regulated neutrophil recruitment is required for brain but not spinal cord inflammation during experimental autoimmune encephalomyelitis. J Immunol. 2014;193: 555-563.

11. Haak S, Croxford AL, Kreymborg K, Heppner FL, Pouly S, Becher B, et al. IL-17A and IL-17F do not contribute vitally to autoimmune neuro-inflammation in mice. J Clin Invest. 2009;119:61-69.

12. Komiyama $\mathrm{Y}$, Nakae S, Matsuki T, Nambu A, Ishigame H, Kakuta S, et al. IL-17 plays an important role in the development of experimental autoimmune encephalomyelitis. J Immunol. 2006;177:566-573.

13. Sonderegger I, lezzi G, Maier R, Schmitz N, Kurrer M, Kopf M. GM-CSF mediates autoimmunity by enhancing IL-6-dependent Th17 cell development and survival. J Exp Med. 2008;205:2281-2294.

14. Lees JR, Golumbek PT, Sim J, Dorsey D, Russell JH. Regional CNS responses to IFN-gamma determine lesion localization patterns during EAE pathogenesis. J Exp Med. 2008;205:2633-2642.

15. Simmons RD, Willenborg DO. Direct injection of cytokines into the spinal cord causes autoimmune encephalomyelitis-like inflammation. J Neurol Sci. 1990;100:37-42.
16. Billiau A, Heremans $H$, Vandekerckhove F, Dijkmans $R$, Sobis $H$, Meulepas $\mathrm{E}$, et al. Enhancement of experimental allergic encephalomyelitis in mice by antibodies against IFN-gamma. J Immunol. 1988;140:1506-1510.

17. TNF neutralization in MS: results of a randomized, placebo-controlled multicenter study. The Lenercept Multiple Sclerosis Study Group and The University of British Columbia MS/MRI Analysis Group. Neurology. 1999;53:457-465.

18. Croxford AL, Spath S, Becher B. GM-CSF in neuroinflammation: licensing myeloid cells for tissue damage. Trends Immunol. 2015;36:651-662.

19. Lee PW, Severin ME, Lovett-Racke AE. TGF- $\beta$ regulation of encephalitogenic and regulatory $\mathrm{T}$ cells in multiple sclerosis. Eur $\mathrm{J}$ Immunol. 2017:47:446-453.

20. Lee PW, Yang Y, Racke MK, Lovett-Racke AE. Analysis of TGF- $\beta 1$ and TGF- $\beta 3$ as regulators of encephalitogenic Th17 cells: implications for multiple sclerosis. Brain Behav Immun. 2015;46:44-49.

21. Huss DJ, Winger RC, Peng $H$, Yang $Y$, Racke MK, Lovett-Racke AE. TGF-beta enhances effector Th1 cell activation but promotes self-regulation via IL-10. J Immunol. 2010;184:5628-5636.

22. Letterio JJ, Geiser AG, Kulkarni AB, Dang H, Kong L, Nakabayashi T, et al. Autoimmunity associated with TGF-b1-deficiency in mice is dependent on MHC class II antigen expression. J Clin Invest. 1996;98: 2109-2119.

23. Gorelik L, Flavell RA. Abrogation of TGFb signaling in T cells leads to spontaneous $\mathrm{T}$ cell differentiation and autoimmune disease. Immunity. 2000;12:171.

24. Schmitt E, Bopp T. Discovery and initial characterization of Th9 cells: the early years. Semin Immunopathol. 2016;39:1-6.

25. Ruocco G, Rossi S, Motta C, Macchiarulo G, Barbieri F, De Bardi M, et al. T helper 9 cells induced by plasmacytoid dendritic cells regulate interleukin-17 in multiple sclerosis. Clin Sci (Lond). 2015;129(4):291-303.

26. Ding X, Cao F, Cui L, Ciric B, Zhang GX, Rostami A. IL-9 signaling affects central nervous system resident cells during inflammatory stimuli. Exp Mol Pathol. 2015:99:570-574.

27. Bsibsi M, Ravid R, Gveric D, Van-Noort JM. Broad expression of Toll-like receptors in the human central nervous system. J Neuropathol Exp Neurol. 2002:61:1013-1021.

28. Miranda-Hernández S, Baxter AG. Role of toll-like receptors in multiple sclerosis. Am J Clin Exp Immunol. 2013;2:75-93.

29. Farez MF, Quintana FJ, Gandhi R, Izquierdo G, Lucas M, Weiner HL. Toll-like receptor 2 and poly(ADP-ribose) polymerase 1 promote central nervous system neuroinflammation in progressive EAE. Nat Immunol. 2009;10:958-964.

30. Correale J, Fiol M, Gilmore W. The risk of relapses in multiple sclerosis during systemic infections. Neurology. 2006;67:652-659.

31. Hossain MJ, Tanasescu R, Gran B. Innate immune regulation of autoimmunity in multiple sclerosis: focus on the role of Toll-like receptor 2. J Neuroimmunol. 2016;304:11-20.

32. Liang $P$, Le W. Role of autophagy in the pathogenesis of multiple sclerosis. Neurosci Bull. 2015;31:435-444.

33. Inoue M, Williams KL, Gunn MD, Shinohara ML NLRP3 inflammasome induces chemotactic immune cell migration to the CNS in experimental autoimmune encephalomyelitis. Proc Natl Acad Sci U S A. 2012;109:10480-10485.

34. Ming X, Li W, Maeda Y, Blumberg B, Raval S, Cook SD, et al. Caspase-1 expression in multiple sclerosis plaques and cultured glial cells. J Neurol Sci. 2002;197:9-18.

35. Seppi D, Puthenparampil M, Federle L, Ruggero S, Toffanin E, Rinaldi F, et al. Cerebrospinal fluid IL-1 $\beta$ correlates with cortical pathology load in multiple sclerosis at clinical onset. J Neuroimmunol. 2014;270:56-60.

36. Inoue $M$, Shinohara ML. The role of interferon- $\beta$ in the treatment of multiple sclerosis and experimental autoimmune encephalomyelitis - in the perspective of inflammasomes. Immunology. 2013;139:11-18.

37. Noroozi S, Meimand HAE, Arababadi MK, Nakhaee N, Asadikaram G. The effects of IFN- $\beta$ 1a on the expression of inflammasomes and apoptosis-associated speck-like proteins in multiple sclerosis patients. Mol Neurobiol. 2017;54:3031-3037.

38. Inoue M, Chen P, Siecinski S, Li Q, Liu C, Steinman L, et al. An interferon-b-resistant and NLRP3 inflammasome-independent subtype of EAE with neuronal damage. Nat Neurosci. 2016:19:1-13.

39. Malhotra S, Río J, Urcelay E, Nurtdinov R, Bustamante MF, Fernández O, et al. NLRP3 inflammasome is associated with the response to IFN- $\beta$ in patients with multiple sclerosis. Brain. 2015;138:644-652.

40. Gross CC, Schulte-Mecklenbeck A, Wiendl H, Marcenaro E, Kerlero-De-Rosbo N, Uccelli A, et al. Regulatory functions of natural killer cells in multiple sclerosis. Front Immunol. 2016;7:606.

41. Ascherio A, Munger KL. Environmental risk factors for multiple sclerosis. Part II: noninfectious factors. Ann Neurol. 2007;61:504-513.

42. Martínez-Rodríguez JE, Cobo-Calvo A, Villar LM, Munteis E, Blanco Y, Rasal $\mathrm{R}$, et al. Adaptive natural killer cell response to cytomegalovirus and disability progression in multiple sclerosis. Mult Scler. 2015;22:741-752.

43. Hu Y, Turner MJ, Shields J, Gale MS, Hutto E, Roberts BL, et al. Investigation of the mechanism of action of alemtuzumab in a human CD52 transgenic mouse model. Immunology. 2009;128:260-270. 
44. Skarica M, Eckstein C, Whartenby KA, Calabresi PA. Novel mechanisms of immune modulation of natalizumab in multiple sclerosis patients. J Neuroimmunol. 2011;235:70-76.

45. Bielekova B, Howard T, Packer AN, Richert N, Ohayon J, Waldmann TA, et al. NIH Public Access. Inflammation. 2010;66:483-489.

46. Gross CC, Schulte-Mecklenbeck A, Rünzi A, Kuhlmann T, Posevitz-Fejfár A, Schwab N, et al. Impaired NK-mediated regulation of T-cell activity in multiple sclerosis is reconstituted by IL-2 receptor modulation. Proc Natl Acad Sci. 2016;113:E2973-E2982.

47. Jiang W, Chai NR, Maric D, Bielekova B. Unexpected role for granzyme $\mathrm{K}$ in CD56bright NK cell-mediated immunoregulation of multiple sclerosis. J Immunol. 2011;187:781-790.

48. Voskuhl RR, Martin R, Bergman C, Dalal M, Ruddle NH, McFarland HF. T helper 1 (Th1) functional phenotype of human myelin basic protein-specific T Iymphocytes. Autoimmunity. 1993:15:137-143.

49. Matusevicius D, Kivisäkk P, He B, Kostulas N, Ozenci V, Fredrikson S, et al. Interleukin-17 mRNA expression in blood and CSF mononuclear cells is augmented in multiple sclerosis. Mult Scler. 1999;5:101-104.

50. Ishizu T, Osoegawa M, Mei FJ, Kikuchi H, Tanaka M, Takakura Y, et al. Intrathecal activation of the IL-17/IL-8 axis in opticospinal multiple sclerosis. Brain. 2005;128:988-1002.

51. Lock C, Hermans G, Pedotti R, Brendolan A, Schadt E, Garren H, et al. Gene-microarray analysis of multiple sclerosis lesions yields new targets validated in autoimmune encephalomyelitis. Nat Med. 2002;8:500-508.

52. Brucklacher-Waldert V, Stuerner K, Kolster M, Wolthausen J, Tolosa E. Phenotypical and functional characterization of $T$ helper 17 cells in multiple sclerosis. Brain. 2009;132:3329-3341.

53. Jovanovic D V, Di-Battista JA, Martel-Pelletier J, Jolicoeur FC, He Y Zhang $\mathrm{M}$, et al. IL-17 stimulates the production and expression of proinflammatory cytokines, IL-beta and TNF-alpha, by human macrophages. J Immunol. 1998;160:3513-3521.

54. Kebir $\mathrm{H}$, Ifergan I, Alvarez JI, Bernard M, Poirier J, Arbour N, et al. Preferential recruitment of interferon-gamma-expressing TH17 cells in multiple sclerosis. Ann Neurol. 2009;66:390-402.

55. Vollmer TL, Wynn DR, Alam MS, Valdes J. A phase 2, 24-week, randomized, placebo-controlled, double-blind study examining the efficacy and safety of an anti-interleukin-12 and -23 monoclonal antibody in patients with relapsing-remitting or secondary progressive multiple sclerosis. Mult Scler. 2011;17:181-191.

56. Segal BM, Constantinescu CS, Raychaudhuri A, Kim L, Fidelus-Gort R, Kasper LH. Repeated subcutaneous injections of IL12/23 p40 neutralising antibody, ustekinumab, in patients with relapsing-remitting multiple sclerosis: a phase II, double-blind, placebo-controlled, randomised, dose-ranging study. Lancet Neurol. 2008;7:796-804.

57. Ramgolam VS, Sha Y, Jin J, Zhang X, Markovic-Plese S. IFN-beta inhibits human Th17 cell differentiation. J Immunol. 2009:183:5418-5427.

58. Durelli L, Conti L, Clerico M, Boselli D, Contessa G, Ripellino P, et al. T-helper 17 cells expand in multiple sclerosis and are inhibited by interferon-beta. Ann Neurol. 2009;65:499-509.

59. Grigoriadis N, Van-Pesch V. A basic overview of multiple sclerosis immunopathology. Eur J Neurol. 2015;22:3-13.
60. Viglietta V, Baecher-Allan C, Weiner HL, Hafler DA. Loss of functional suppression by $C D 4+C D 25+$ regulatory $T$ cells in patients with multiple sclerosis. J Exp Med. 2004;199:971-979.

61. Haas J, Fritzsching B, Trübswetter P, Korporal M, Milkova L, Fritz B, et al. Prevalence of newly generated naive regulatory $T$ cells (Treg) is critical for Treg suppressive function and determines Treg dysfunction in multiple sclerosis. J Immunol. 2007;179:1322-1330.

62. Calabresi PA, Fields NS, Maloni HW, Hanham A, Carlino J, Moore J, et al. Phase 1 trial of transforming growth factor beta 2 in chronic progressive MS. Neurology. 1998;51:289-292.

63. Braitch M, Harikrishnan S, Robins RA, Nichols C, Fahey AJ, Showe L, et al. Glucocorticoids increase CD4+CD25high cell percentage and Foxp3 expression in patients with multiple sclerosis. Acta Neurol Scand. 2009;119:239-245.

64. Sinha S, Boyden AW, Itani FR, Crawford MP, Karandikar NJ. CD8+ T-cells as immune regulators of multiple sclerosis. Front Immunol. 2015;6:619.

65. Balashov KE, Khoury SJ, Hafler DA, Weiner HL. Inhibition of T cell responses by activated human CD8+ $T$ cells is mediated by interferon-gamma and is defective in chronic progressive multiple sclerosis. J Clin Invest. 1995;95:2711-2719.

66. Baughman EJ, Mendoza JP, Ortega SB, Ayers CL, Greenberg BM, Frohman EM, et al. Neuroantigen-specific CD8+ regulatory T-cell function is deficient during acute exacerbation of multiple sclerosis. J Autoimmun. 2011;36:115-124.

67. Ayers CL, Mendoza JP, Sinha S, Cunnusamy K, Greenberg BM, Frohman EM, et al. Modulation of immune function occurs within hours of therapy initiation for multiple sclerosis. Clin Immunol. 2013;147:105-119.

68. Aristimuño C, Navarro J, De-Andrés C, Martínez-Ginés ML, Giménez-Roldán S, Fernández-Cruz E, et al. Expansion of regulatory CD8+ T-lymphocytes and fall of activated CD8+ T-lymphocytes after iv methyl-prednisolone for multiple sclerosis relapse. J Neuroimmunol. 2008;204:131-135

69. Cepok S, Jacobsen M, Schock S, Omer B, Jaekel S, Böddeker I, et al. Patterns of cerebrospinal fluid pathology correlate with disease progression in multiple sclerosis. Brain. 2001;124:2169-2176.

70. Krumbholz M, Theil D, Cepok S, Hemmer B, Kivisäkk P, Ransohoff RM, et al. Chemokines in multiple sclerosis: CXCL12 and CXCL13 up-regulation is differentially linked to CNS immune cell recruitment. Brain. 2006;129:200-211.

71. Howell OW, Reeves CA, Nicholas R, Carassiti D, Radotra B, Gentleman $\mathrm{SM}$, et al. Meningeal inflammation is widespread and linked to cortical pathology in multiple sclerosis. Brain. 2011;134:2755-2771.

72. Roche PA, Furuta K. The ins and outs of MHC class II-mediated antigen processing and presentation. Nat Rev Immunol. 2015;15:203-216.

73. Hauser S, Waubant E, Arnold DL, Vollmer T, Antel J, Fox RJ, et al. $B$-cell depletion with rituximab in relapsing-remitting multiple sclerosis. N Engl J Med. 2008;358:676-688.

74. Kappos L, Li D, Calabresi PA, O'Connor P, Bar-Or A, Barkhof F, et al. Ocrelizumab in relapsing-remitting multiple sclerosis: a phase 2, randomised, placebo-controlled, multicentre trial. Lancet. 2011;378:1779-1787. 